\title{
GENTAMYCIN-INDUCED NEPHROTOXICITY IN CHICKENS: MODULATORY ROLE OF MORINGA OLEIFERA
}

\author{
MOHAMED FAHMY ABOU ELAZAB ${ }^{*}$ and NAGWAN EL-HABASHI ${ }^{* *}$ \\ *Department of Clinical Pathology, Faculty of Veterinary Medicine, Kafr Elsheikh University, Kafr Elsheikh, Egypt. \\ ** Department of Pathology, Faculty of Veterinary Medicine, Kafr Elsheikh University, Kafr Elsheikh Egypt. \\ *** Corresponding author: Nagwan M. El-Habashi, Department of Pathology, Faculty of Veterinary Medicine, Kafr Elsheikh \\ University, Kafr Elsheikh, Egypt. \\ Tel, Fax number: +20-473231311 \\ Email: nagwan_hab@yahoo.com
}

\section{ABSTRACT}

Received at: 19/10/2014

Accepted: 8/1/2015
The aim of the present study was to determine whether Moringa oleifera (MOR) leaf powder, have a modulatory effect against gentamicin (GEN)-induced nephrotoxicity in chickens or not. Twenty laying hens were equally divided into four groups: First group $(\mathrm{CON})$ received standard basal diet only. Second group (GEN) was injected with GEN $(50 \mathrm{mg} / \mathrm{kg}$ body weight, intramuscularly (i.m.), twice daily, for 5 consecutive days). Third group (GEN+MOR) was supplemented with MOR leaf powder $(10 \mathrm{gm} / \mathrm{kg}$ diet) daily for 12 consecutive days and injected with GEN (50mg/kg body weight, i.m., twice daily, for 5 consecutive days) starting from the day 8. Fourth group (MOR) was supplemented with MOR leaf powder $(10 \mathrm{gm} / \mathrm{kg}$ diet) daily for 12 consecutive days. GEN administration increased serum creatinine $(\mathrm{Cr})$, blood urea nitrogen (BUN), and malonaldehyde (MDA) and decreased total protein, albumin, reduced glutathione $(\mathrm{GSH})$ content as well as superoxide dismutase (SOD), glutathione peroxidase (GPx), and catalase (CAT) activities indicating nephrotoxicity. Furthermore, histopathological findings revealed marked tubular vacuolar degeneration, focal interstitial mononuclear cells infiltrations, congestion, focal cystic change and tubular necrosis in GEN-treated kidneys. However, MOR leaf powder supplementation with GEN administration caused significant decrease of serum $\mathrm{Cr}, \mathrm{BUN}$, and MDA and increase of total protein, albumin, GSH, SOD, GPx, and CAT compared with GEN alone. Moreover, GEN+MOR treated group showed slight focal interstitial mononuclear cells infiltrations in renal tissues. These findings suggested that dietary supplementation of MOR leaf powder may prevent or reduce the GEN-induced nephrotoxicity.

Keywords: Chicken; Gentamicin; Moringa oleifera; Nephrotoxicity

\section{INTRODUCTION}

Currently, antibiotics are used on a large scale to treat or prevent infections in poultry industry. Gentamicin (GEN), bactericidal aminoglycoside antibiotic, is an important therapeutic agent that commonly used in poultry farms. GEN is effective against many gram-negative and gram-positive bacteria. However, it resulted in nephrotoxicity even when birds are treated with low doses (Flammer, 1994). Gentamycin exhibits concentration dependent microbial killing where the high drug concentration is the best way to obtain rapid bactericidal effects (Hagen and Oymar, 2009). The higher doses are more preferable than low doses; however, there is no accurate data about the corresponding toxicities.
GEN is commonly used in birds; but resulted in kidney enlargement and changes resembling other causes of renal failure (Schmidt et al., 2003). GEN is an effective and economical drug used to control infectious diseases in poultry but is highly toxic and had slow clearance from the body (Islam et al., 2011). Experimental GEN toxicity has been reported in growing cockerels (Khan et al., 2008), day old broiler chicks (Saleemi et al., 2009), in commercial layers (Islam et al., 2011) and growing broilers (Javed et al., 2013). GEN is extensively used in combination with other antibiotics in poultry practice in Egypt. Gentamycin is used repeatedly for treatment of different bacterial infections in laying hens, its continuous use lead to severe nephrotoxicity that heavily influences their welfare and eventually may even lead to high mortality (Islam et al., 2011). 
The mechanism of GEN-induced nephrotoxicity is still unknown. However, reactive oxygen species (ROS) appear to be involved in the pathophysiology of GEN-induced nephrotoxicity (Yang et al., 1995; Walker et al., 1999; Mart1'nez-Salgado et al., 2002 and Morales et al., 2010). Further more, several recent studies had shown that co-treatment with different antioxidants is useful for prevention or amelioration of GEN-induced nephrotoxicity (Kadkhodaee et al., 2007; Karadeniz et al., 2008; Koyner et al., 2008; Yaman and Balikci, 2010 and Kang et al., 2013).

Moringa oleifera (MOR) is a highly valued medicinal plant where its various parts have been used as food and medicine from a long time. The nutritional and medicinal benefits of MOR have been attributed to its roots, bark, leaves, flowers, fruits, and seeds (Ramachandran et al., 1980; Anwar et al., 2007 and Kumar et al., 2010). Phytochemical analyses have shown that MOR leaves are particularly rich in essential minerals, vitamins $\mathrm{A}$ and $\mathrm{D}$, essential amino acids, as well as potent antioxidants such as $\beta$ carotene, vitamin $\mathrm{C}$, and flavonoids (Bennett et al., 2003; Aslam et al., 2005; Manguro and Lemmen, 2007; Amaglo et al., 2010 and Gowrishankar et al., 2010).

MOR relatively contains high antioxidant activity in its leaves, flowers, and seeds (Chumark et al., 2008; Sreelatha and Padma, 2009; Verma et al., 2009 and Atawodi et al., 2010). The extracts of MOR both mature and tender leaves have potent antioxidant activity against free radicals, prevent oxidative damage to major biomolecules and afford significant protection against oxidative damage (Sreelatha and Padma, 2009). Therefore, the present study was designed to investigate the possible modulatory effect of MOR leaf powder against GEN-induced nephrotoxicity in chickens.

\section{MATERIALS and METHODS}

\section{Animals}

Twenty laying hens (Dokki-4 strain; age, 15 months) were obtained from animal production center, Kafr Elshiekh, Egypt. Chickens maintained under standardized environmental conditions on $12 \mathrm{~h}$ light/dark cycle under a temperature of $25 \pm 2^{\circ} \mathrm{C}$ and provided with commercial balanced diet and tap water, adlibitum throughout the experiment. Animals were acclimatized for two weeks before starting the experiment. All chicken's related procedures were carried out in accordance with appropriate methods, and an approval was obtained from the ethical committee of Kafr Elshiekh University.

\section{Experimental design}

Chickens were randomly divided into four groups of five birds each. The first group $(\mathrm{CON})$ received standard basal diet for 12 days. The second group (GEN), received GEN (50 mg/kg body weight, i.m., twice daily for 5 consecutive days. Gentamicin sulfate was purchased from Bremer Pharma, GmbH, Germany. The third group (GEN+MOR) was given MOR leaf powder $(10 \mathrm{gm} / \mathrm{kg}$ diet/day $)$ for 12 consecutive days and injected with GEN $(50 \mathrm{mg} / \mathrm{kg}$ body weight, i.m., twice daily, for 5 consecutive days) starting from the day 8. The fourth group (MOR) was supplemented with MOR leaf powder $(10 \mathrm{gm} / \mathrm{kg} \mathrm{diet} /$ day) for 12 consecutive days.

\section{Blood collection}

Blood samples were collected from the wing veins of all laying hens $12 \mathrm{~h}$ from the last dose of gentamycin. Approximately $4 \mathrm{ml}$ of blood were collected per hen. Serum was separated from clotted blood by centrifugation at $3,000 \times \mathrm{g}$ for 20 minutes and stored at $-20^{\circ} \mathrm{C}$ until use.

\section{Biochemical meausurment: \\ 4.1. Estimation of kidney markers:}

Creatinine $(\mathrm{Cr})$; blood urea nitrogen $(\mathrm{BUN})$, total protein and albumin were determined by using commercially available diagnostic kits (Biorex Diagnostics, Ltd, United Kingdom ${ }^{\circledR}$ ).

\subsection{Estimation of oxidative stress markers Measurement of MDA:}

MDA (an indicator of lipid peroxidation) was calorimetrically determined according to the method adapted by Esterbauer et al. (1982). This method is based on the measurement of malondialdehyde (MDA) as one of the main end products of lipid peroxidation by the thiobarbituric acid test. Thiobarbituric acid reacts with malondialdehyde in acidic medium at $95{ }^{\circ} \mathrm{C}$ for 30 minute to form thiobarbituric acid reactive product. The absorbance of the resultant color product measured at $534 \mathrm{~nm}$.

\section{Measurement of GSH:}

GSH was determined according to the methods of Beutler et al. (1963). This method is based on spectrophotometrically measurement of the yellow color of 2-nitro-5-thiobenzoic acid which was produced from the following reaction: Glutathione + 5,5'-dithiobis (2-nitrobenzoic acid) (DTNB) 2-nitro5-thiobenzoic acid + glutathione disulfide (GSSG).

\section{Measurement of SOD:}

SOD activity was determined spectrophotometrically according to the reported method (Paoletti and Mocali, 1990). The method is based on the ability of SOD to inhibit the oxidation of NADH, mediated by superoxide radical. The addition of SOD to the reaction mixture causes proportional inhibition of the rate of $\mathrm{NADH}$ oxidation. The unit of activity is defined as the amount of enzyme causing 50 percent inhibition of the rate of the superoxide-driven NADH oxidation. 


\section{Measurement of GPx:}

GPx activity was assayed according to the method of Gross et al. (1967). The activity of GPx was measured directly by determining the amount of unconsumed reduced glutathione (GSH) remaining at specific time intervals in the presence of small amounts of peroxide.

\section{Measurement of CAT:}

CAT activity was determined by the method described by Sinha, (1972). The dichromate/ acetic acid reagent can be thought of as a "stop bath" for catalase activity. As soon as enzyme reaction mixture hits the acetic acid, its activity is inhibited, any hydrogen peroxide, which has not been split by catalase will react with dichromate to give a blue precipitate of perchromic acid. This unstable precipitate was then decomposed by heating to give the green color solution which was measured spectrophotometery at $570 \mathrm{~nm}$.

All chemicals used in this study were of analytical grade.

\section{Histopathological examination}

Animals from each group were sacrificed on the day of bleeding and the kidneys were isolated. Tissue specimens were fixed immediately in $10 \%$ formalin and processed for histopathological studies, using routine paraffin embedding method. Sections of $4 \mu \mathrm{m}$ thick were cut and stained using hematoxylin and eosin as mentioned by Bancroft and Gamble, (2007) and examined microscopically. For each slide, minimum of 20 microscopic field (20X)/slide were examined and evaluated. The severity of changes is scored according to the following scale: no change $(-)$, mild, $<10 \%$ of tubules showed changes $(+)$, moderate changes affecting $10-25 \%$ of tubules $(++)$, severe damage affecting $25-50 \%$ of tubules (+++).

\section{Statistical analysis}

Statistical analysis was carried out by using the SPSS for windows software, version16 (SPSS Inc., Chicago, IL, USA). Groups data were compared by one-way analysis of variance (ANOVA), followed by LSD test. The statistical significance was accepted at a level of $P<0.05$.

\section{RESULTS}

1. Effect of MOR leaf powder supplementation on $\mathrm{Cr}$, BUN, total protein and albumin levels in GEN-treated chickens; Firstly, serum Cr and BUN levels were measured. Chickens treated with GEN alone showed significant increase in the serum levels of $\mathrm{Cr}$ and BUN compared to control group and MOR only-treated group $\quad(p<0.05)$. However, Supplementation of MOR leaf powder in the GEN+MOR-treated group significantly reduced the serum levels of $\mathrm{Cr}$ and BUN compared to GENtreated group $(p<0.05)$ (table 1). Also, chickens treated with GEN alone showed significant decrease in the serum levels of total protein and albumin compared to control group and MOR only-treated group $(p<0.05)$. However, Supplementation of MOR leaf powder in the GEN+MOR-treated group significantly increase the serum levels of total protein and albumin compared to GEN-treated group $(p<0.05)$ (table 1).

2. Effect of MOR leaf powder supplementation on oxidative stress markers in GEN-treated chickens: MDA, GSH, SOD, GPx, and CAT were measured in the serum of all chickens as markers for oxidative stress. Data presented in table 2 showed that chickens treated with GEN alone showed significant increase of MDA concentration, in addition to, significant decrease in GSH concentration as well as SOD, GPX, and CAT activities compared to normal control group and MOR-only treated group $(p<0.05)$. In contrast, MOR+GEN-treated group showed significant lower concentrations of MDA and higher GSH concentrations as well as serum activities of SOD, GPX, and CAT as compared to GEN- treated group $(p<0.05)$.

\section{Effect of MOR leaf powder supplementation on} renal tissue damage induced by GEN: Histopathological findings of kidney sections of control and MOR-treated chickens showed normal morphological appearances except mild vacuolar degeneration of renal tubular cells was observed in MOR-treated chicken (Fig. 1), whereas GEN-treated group revealed marked enlargement, congestion and greenish discoloration grossly and microscopically, marked vacuolar degeneration of the proximal convoluted tubular epithelium (Fig. 2A) as well as focal interstitial mononuclear cells infiltrations (Fig. 2B) sometimes admixed with heterophils were observed. Marked congestion was also observed together with sloughing of the degenerated renal tubular cells in the lumen of the affected tubules. Brown circular golden crystals were also observed either free in the lumen (Fig. 2C) or in the proximal convoluted epithelial cells or engulfed by heterophils. Focal cystic change as well as focal tubular necrosis was also observed. Kidney of GEN+MOR-treated chicken demonstrated focal interstitial mononuclear cells infiltrations (Fig. 3) as well as vacuolar degeneration of the renal tubules. The severity degrees of histopathological changes in different treatment groups were summarized in table 3 . 
Table 1: Effect of Moringa oleifera leaf powder supplementation on creatinine, blood urea nitrogen, total protein and albumin in gentamycin-treated chickens.

\begin{tabular}{ccccc}
\hline Groups & $\begin{array}{c}\text { Creatinine } \\
(\mathrm{mg} / \mathrm{dl})\end{array}$ & Blood urea nitrogen $(\mathrm{mg} / \mathrm{dl})$ & Total protein $(\mathrm{gm} / \mathrm{dl})$ & Albumin $(\mathrm{gm} / \mathrm{dl})$ \\
\hline CON & $0.57 \pm 0.02$ & $5.90 \pm 0.13$ & $4.04 \pm 0.03$ & $2.72 \pm 0.01$ \\
\hline GEN & $0.78 \pm 0.02^{*}$ & $10.93 \pm 0.78^{*}$ & $2.32 \pm 0.01^{*}$ & $0.86 \pm 0.01^{*}$ \\
\hline GEN+MOR & $0.45 \pm 0.01$ & $5.84 \pm 0.55$ & $4.14 \pm 0.17$ & $1.36 \pm 0.03$ \\
\hline MOR & $0.57 \pm 0.01$ & $6.08 \pm 0.10$ & $4.10 \pm 0.04$ & $2.60 \pm 0.17$ \\
\hline
\end{tabular}

a) Data are expressed as means $\pm \mathrm{SD}$.

b)*: Significantly different from control $(\mathrm{p}<0.05)$.

Table 2: Effect of Moringa oleifera leaf powder supplementation on oxidative stress markers in gentamicintreated chickens.

\begin{tabular}{cccccc}
\hline Groups & $\begin{array}{c}\text { MDA } \\
(\mathrm{nmol} / \mathrm{ml})\end{array}$ & $\begin{array}{c}\text { GSH } \\
(\mu \mathrm{mol} / \mathrm{ml})\end{array}$ & $\begin{array}{c}\text { SOD } \\
(\mathrm{U} / \mathrm{ml})\end{array}$ & $\begin{array}{c}\text { GPx } \\
(\mathrm{U} / \mathrm{ml})\end{array}$ & CAT $(\mathrm{nmol} / \mathrm{ml})$ \\
\hline CON & $7.95 \pm 0.49$ & $1.70 \pm 0.16$ & $0.75 \pm 0.03$ & $1.28 \pm 0.03$ & $1.40 \pm 0.06$ \\
\hline GEN & $11.64 \pm 0.26^{*}$ & $0.87 \pm 0.13^{*}$ & $0.63 \pm 0.01^{*}$ & $1.20 \pm 0.00^{*}$ & $1.22 \pm 0.01^{*}$ \\
\hline GEN+MOR & $8.95 \pm 1.10$ & $2.10 \pm 0.33$ & $0.65 \pm 0.09$ & $1.28 \pm 0.04$ & $1.30 \pm 0.06$ \\
\hline MOR & $7.75 \pm 0.02$ & $6.00 \pm 0.96$ & $0.73 \pm 0.01$ & $1.47 \pm 0.10$ & $1.49 \pm 0.02$ \\
\hline
\end{tabular}

a) Data are expressed as means \pm SD.

b)*: Significantly different from control $(\mathrm{p}<0.05)$.

Table 3: The severity of histopathological changes observed in the kidneys of chicken treated with gentamycin with or without MOLP.

\begin{tabular}{|c|c|c|c|c|c|c|c|}
\hline Chicken No. & $\begin{array}{c}\text { Vacuolar } \\
\text { and hydropic } \\
\text { degeneration }\end{array}$ & $\begin{array}{c}\text { Interstitial } \\
\text { mononuclear } \\
\text { cells infiltrations }\end{array}$ & $\begin{array}{l}\text { Tubular } \\
\text { necrosis }\end{array}$ & Congestion & $\begin{array}{l}\text { Cystic } \\
\text { tubular } \\
\text { change }\end{array}$ & $\begin{array}{l}\text { Brown } \\
\text { circular } \\
\text { crystal }\end{array}$ & $\begin{array}{c}\text { Cellular } \\
\text { casts }\end{array}$ \\
\hline CON1 & - & - & - & - & - & - & - \\
\hline CON2 & - & - & - & - & - & - & - \\
\hline CON3 & - & - & - & - & - & - & - \\
\hline CON4 & - & - & - & - & - & - & - \\
\hline CON5 & - & - & - & - & - & - & - \\
\hline MOR1 & - & - & - & - & - & - & - \\
\hline MOR2 & - & - & - & - & - & - & - \\
\hline MOR3 & + & - & - & - & - & - & - \\
\hline MOR4 & + & - & - & - & - & - & - \\
\hline MOR5 & + & - & - & - & - & - & - \\
\hline GEN1 & +++ & + & ++ & +++ & + & - & - \\
\hline GEN2 & +++ & +++ & + & +++ & +++ & +++ & +++ \\
\hline GEN3 & +++ & +++ & +++ & +++ & +++ & +++ & +++ \\
\hline GEN4 & +++ & +++ & +++ & +++ & +++ & +++ & +++ \\
\hline GEN5 & +++ & ++ & ++ & +++ & + & - & ++ \\
\hline GEN+MOR1 & - & - & - & - & - & - & - \\
\hline GEN+MOR2 & +++ & +++ & - & + & + & - & + \\
\hline GEN+MOR3 & + & + & - & + & - & - & - \\
\hline GEN+MOR4 & ++ & ++ & - & + & - & - & + \\
\hline GEN+MOR5 & + & + & - & + & - & - & - \\
\hline
\end{tabular}

The degrees of severity are: no change (-), mild (+), moderate $(++)$ and severe $(+++)$ 


\section{Figure captions}

Fig. 1: Representative micrograph for the kidney lesions following treatment of chickens with $\operatorname{MOR}(10 \mathrm{gm} / \mathrm{kg}$ diet for 12 consecutive days). The kidney showing normal renal tubular and glomeruli architecture with very mild vacuolar degeneration of renal tubular cells (H\&E, X 200).

Fig. 2: Representative micrographs for the kidney lesions following treatment of chickens with GEN $(50 \mathrm{mg} / \mathrm{kg}$ body weight, i.m., twice daily, for 5 consecutive days). (A) The kidney showing marked vacuolar degeneration of the proximal convoluted tubular epithelium (H\&E, X 400), (B) The kidney showing Focal interstitial mononuclear cells infiltrations as well as vacuolar degeneration of the proximal convoluted tubular epithelium (H\&E, $\mathrm{X}$ 200), (C) The kidney showing Brown circular golden crystals (arrow) in the lumen of the proximal convoluted tubules together with sloughed necrotic epithelial cells (H\&E, X 400).

Fig. 3: Representative micrograph for the kidney lesions following treatment of chickens with GEN+MOR (MOR leaf powder, $10 \mathrm{gm} / \mathrm{kg}$ diet/day for 12 consecutive days and injected with GEN, $50 \mathrm{mg} / \mathrm{kg}$ body weight, i.m., twice daily for 5 consecutive days). The kidney showing focal interstitial mononuclear cells infiltrations as well as mild vacuolar degeneration of the proximal convoluted tubular epithelium (H\&E, X 200).
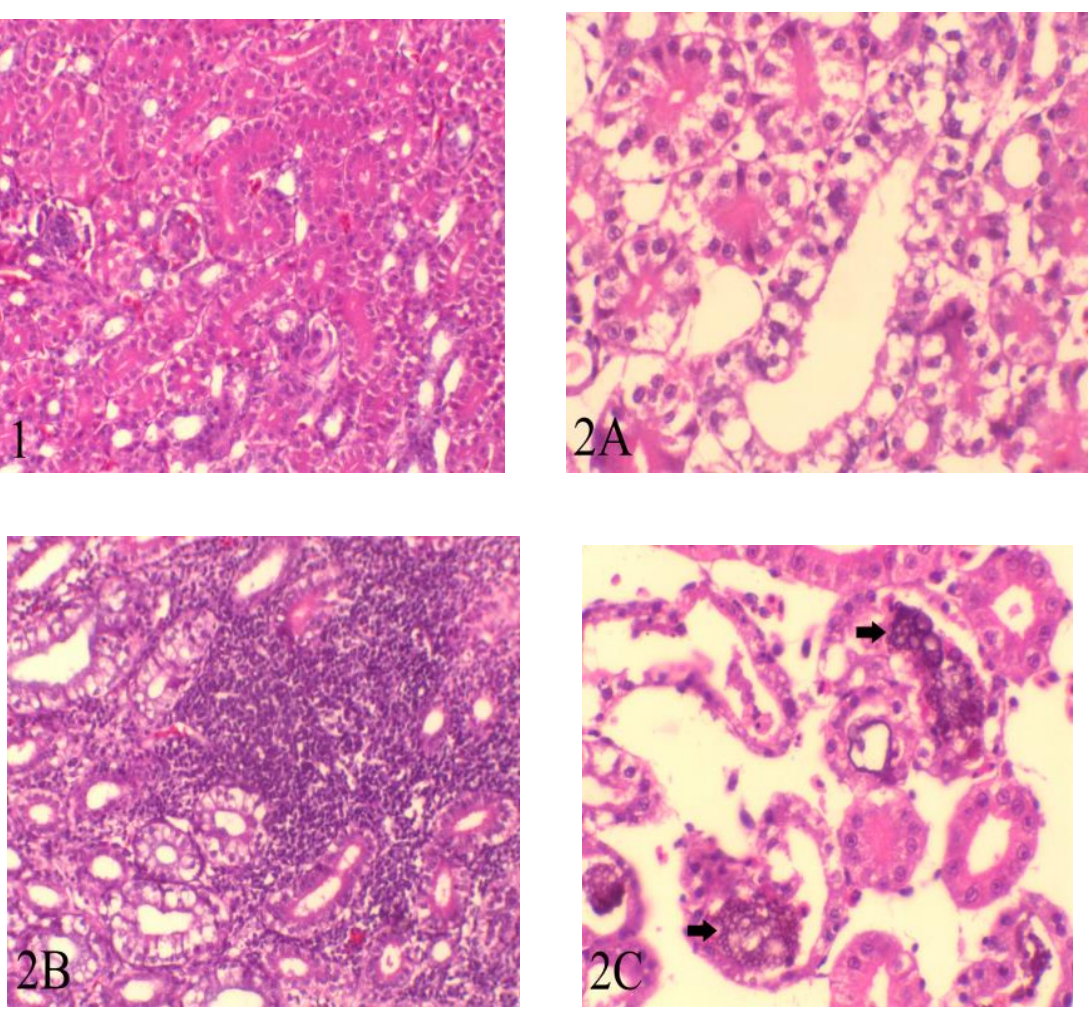

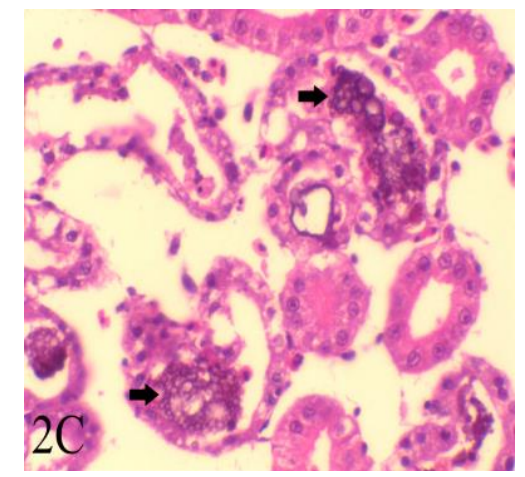

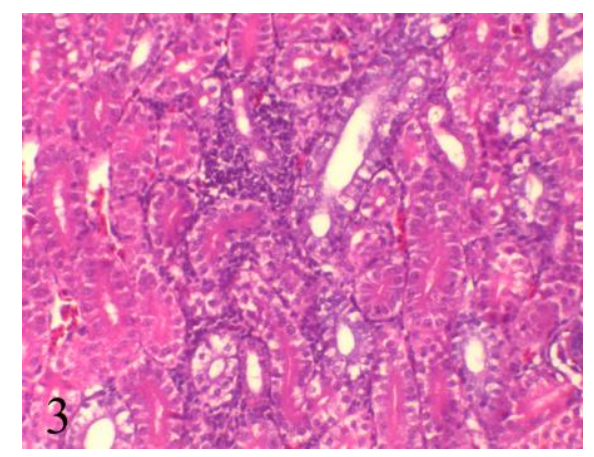




\section{DISCUSSION}

GEN is one of the main aminoglycosides antibiotics in use against gram-negative infection in animal and poultry medicine. However, nephrotoxicity represents the most common side effect of GEN administration (Tulkens, 1999). Scanty information is available about toxicopathological changes associated with GEN toxicity in avian species. Recently, administration of GEN at a dose of 50 $\mathrm{mg} / \mathrm{kg}$ and above was found to be toxic to the birds (Khan et al., 2008 and Saleemi et al., 2009). Thus using the same dose in the present study was to evaluate GEN induced nephrotoxicity on the basis of biochemical estimation of renal damage markers, oxidative damage markers and histopathological examination of treated kidney as well as possible modulatory effect of MOR leaf powder against such toxicity. Also, changes in biochemical parameters were correlated with renal histopathological results.

The results of present study showed that administration of GEN alone produced kidney damage as indicated from the high levels of serum $\mathrm{Cr}$ and BUN. Similar observations had shown that GEN administration leaded to nephrotoxicity that was characterized by an increase in serum $\mathrm{Cr}$ and BUN levels in rats (Afzal et al., 2004; Romero et al., 2009; Tavafi and Ahmadvand, 2011) and in birds (Bird et al., 1983, Itoh and okada, 1993, Khan et al., 2008, Saleemi et al., 2009 and Javed et al., 2013). Also, serum total protein and albumin were measured. GEN-treated group showed a significant reduction in the total protein and albumin levels when compared to control group. Decreased serum total protein and albumin levels were previously reported in birds following GEN administration (Bird et al., 1983, Itoh and okada, 1993, Khan et al., 2008, Saleemi et al., 2009 and Javed et al., 2013). Hypoproteinemia and Hypoalbuminemia may be caused by decrease in synthesis of serum proteins associated with severe hepatocellular disease or excessive excretion/loss through damaged kidneys (Tennant and Center, 2008). But, MOR leaf powder supplementation impeded the decrease in total protein and albumin caused by gentamicin. This modulatory effect may be due to its high content of antioxidants and essential amino acids.

The mechanism of GEN-induced nephrotoxicity is not yet completely clear, however, several reports have been documented that ROS and free radicals play an important role in GEN-induced nephrotoxicity (Nakajima et al., 1994; Yang et al., 1995; Walker et al., 1999; Martínez-Salgado et al., 2002 and Morales et al., 2010). ROS and free radicals are highly reactive molecules which lead to excessive oxidation of cellular macromolecules such as DNA, proteins, and lipids. All cells are variably capable of endogenous self protection against this stress through the actions of enzymes such as SOD, GPx, and CAT as well as through reducing molecules such as GSH. Cellular inability to reduce ROS leads to oxidative stress (Fulda et al., 2010).

Evaluations of MDA, GSH concentrations and activities of SOD, GPx, and CAT have been used as markers of oxidative stress and tissue damage. GEN administration induced oxidative renal damage, as evidenced by a significant increase in serum MDA concentration and a significant decrease in GSH content, as well as significant decrease of SOD, GPx, and catalase activities. This result indicates an increase in the generation of free radicals and antioxidant enzymes depletion as a result of the process of combating oxidative stress. Similar studies have been shown that GEN-induced kidney damage is associated with lipid peroxidation and reduction of the kidney GSH content and reduction of the antioxidant enzyme activities such as GPx, SOD, and catalase (Polat et al., 2006; Karadeniz et al., 2008; Khan et al., 2009; Lee et al., 2012 and Kang et al., 2013).

However, MOR leaf powder supplementation induced a significant decrease in the MDA concentration and efficiently improved the GPx, SOD, and catalase activities. This effect might be due to its antioxidant properties. Recent findings have been demonstrated that the extracts of MOR leaves have potent antioxidant activity against free radicals, prevent oxidative damage to major biomolecules and afford significant protection against oxidative damage (Bajpai, 2005; Sreelatha and Padma, 2009 and Sharma and Singh, 2010). These properties may be mediated through scavenging of the free radicals (Verma et al., 2009).

The above mentioned results were confirmed by the histopathological results, as evidenced by a decrease in the incidence and severity of GEN induced-renal histopathological lesions in GEN+MOR group. Vacuolar degeneration of the proximal convoluted tubular epithelium, interstitial mononuclear cells infiltrations in focal manner between the tubules in the corticomedullary junction, cystic luminal dilatation as well as focal tubular necrosis observed in the present study in GEN treated group were similar to those observed by previous reports in animals (Yoshiyama et al., 1992, Shirwaikar et al., 2003 and Abdel Raheem et al., 2009) and birds (Khan et al., 2008 and Saleemi et al., 2009). Brown circular golden pigments or crystals either free in the lumen or in the renal epithelial cells of the proximal convoluted tubules observed in the present study may be GEN crystals or metabolites as previously mentioned that aminoglycosides throughout the endocytic pathway are taken up into the epithelial cells of the renal proximal tubules and stay there for a long time, which leads to nephrotoxicity (Nagai and 
Takano, 2004 and Nagai, 2006). It is also evidenced that the renal accumulation of GEN is implicated in the induction of nephrotoxicity (Watanabe et al., 2004). Moreover, acidic phospholipids, broadly distributed in the plasma membranes in various tissues, were considered to be the binding site of aminoglycosides in brush-border membrane of proximal tubular cells (Nagai and Takano, 2004, Nagai, 2006). The majority of administrated GEN enters specifically the proximal tubular epithelial cells, binds to anionic phospholipids in the target cells inducing lysosomal phospholipidosis leading to abnormalities in the function and metabolism of multiple intracellular membranes and organelles then developed injury in the proximal tubular epithelial cells of kidney that caused acute renal failure (Swan, 1997and Sandhu et al., 2007).

In conclusion, MOR leaf may have protective effect against GEN-induced nephrotoxicity in chickens, possibly by inhibiting lipid peroxidation, enhancing renal glutathione content and activity of antioxidant enzymes.

\section{CONFLICTS OF INTEREST}

None declared.

\section{FINANCIAL SUPPORT}

The authors received no financial support for the research, authorship, and/or publication of this article.

\section{REFERENCES}

Abdel Raheem, IT.; Abdel Ghany, AA. and Mohamed, $G A$. (2009): Protective effect of quercetin against gentamicin-induced nephrotoxicity in rats. Biol Pharm Bull. 32: 61-67.

Afzal, M.; Khan, NA.; Ghufran, A.; Iqbal, A. and Inamuddin, M. (2004): Diuretic and nephroprotective effect of Jawarish Zarooni Sada - a polyherbal unani formulation. J. Ethnopharmacol.91: 219-223.

Amaglo, NK.; Bennett, RN.; LoCurto, RB.; Rosa, EAS.; LoTurco, V.; Giuffrid, A.; LoCurto, A.; Crea, F. and Timpo, GM. (2010): Profiling selected phytochemicals and nutrients in different tissues of the multi purpose tree Moringa oleifera L. grown in Ghana. Food Chem. 122: 1047-1054.

Anwar, F.; Latif, S.; Ashraf, M. and Gilani, AH. (2007): Moringa oleifera: a food plant with multiple medicinal uses. Phytother Res.21: 17-25.

Aslam, M.; Anwar, F.; Nadeem, R.; Rashid, U.; Kazi, TG. and Nadeem, M. (2005): Mineral composition of Moringa oleifera leaves and pods from different regions of Punjab, Pakistan. Asian J. Plant Sci. 4: 417-421.

Atawodi, SE.; Atawodi, JC.; Idakwo, GA.; Pfundstein, B.; Haubner, R.; Wurtele, G.; Bartsch, H. and Owen, RW. (2010): Evaluation of the polyphenol content and antioxidant properties of methanol extracts of the leaves, stem, and root barks of Moringa oleifera Lam. J. Med. Food, 13: 710-716.

Bajpai, M.; Pande, A.; Tewari, SK. and Prakash, D. (2005): Phenolic contents and antioxidant activity of some food and medicinal plants. Int. J. Food Sci. Nutr. 56: 287-291.

Bancroft, JD. and Gamble, M. (2007): Theory and Practice of Histological Techniques. 5th Ed; Churchill Livingstone, London, UK. p. 125-138.

Bennett, RN.; Mellon, FA.; Foidl, N.; Pratt, JH.; Dupont, MS.; Perkins, L. and Kroon, PA. (2003): Profiling glucosinolates and phenolics in vegetative and reproductive tissues of the multi-purpose trees Moringa oleifera L. (horse radish tree) and Moringa stenopetala L. J. Agric. Food Chem. 51: 3546-3553.

Beutler, E.; Duron, O. and Kelly, BM. (1963): Improved method for the determination of blood glutathione. J Lab Clin Med. 61: 882-888.

Bird, JE.; Walser, MM. and Duke, GE. (1983): Toxicity of gentamicin in red tailed hawks. Am. J. Vet. Res. 44 1289-1293.

Chumark, P.; Khunawat, P.; Sanvarinda, Y.; Phornchirasilp, S.; Morales, NP.; PhivthongNgam, L.; Ratanachamnong, P.; Srisawat, S. and Pongrapeeporn, KU. (2008): The in vitro and ex vivo antioxidant properties, hypolipidaemic and antiatherosclerotic activities of water extract of Moringa oleifera Lam. leaves. J. Ethnopharmacol. 116: 439-446.

Esterbauer, H.; Cheeseman, KH.; Danzani, MU.; Poli, G. and Slater, TF. (1982): Separation and characterization of the aldhyde products of $\mathrm{ADP} / \mathrm{Fe} 2+\mathrm{C}$ stimulated lipid peroxidation in rat liver microsomes. Biochem. J. 208: 129-140.

Flammer K. Antimicrobial Therapy. In. Branson, W.R.; Greg, J.H. and Linda, R.H. (Eds.) (1994): Avian Medicine: Principles and Application. Wingers Publishing, Inc., Lake worth, Florida. p.434-456.

Fulda, S.; Gorman, AM.; Hori, O. and Samali, A. (2010): Cellular Stress Responses: Cell Survival and Cell Death. International Journal of Cell Biology, 23 pages. doi: 10.1155/2010/214074.

Gowrishankar, R.; Kumar, M.; Menon, V.; Divi, SM.; Saravanan, M.; Magudapathy, P.; Panigrahi, $B K$.; Nair, KG. and Venkataramaniah, $K$. (2010): Trace element studies on Tinospora 
cordifolia (Menispermaceae), Ocimum sanctum (Lamiaceae), Moringa oleifera (Moringaceae), and Phyllanthus niruri (Euphorbiaceae) using PIXE. Biol. TraceElem.Res. 133: 357-363.

Gross, RT.; Bracci, R.; Rudolph, N.; Schroeder, E. and Kochen, JA. (1967): Hydrogen peroxide toxicity and detoxification in the erythrocytes of newborn infants. Blood, 29: 481-493.

Hagen, I. and Oymar, K. (2009): Pharmacological differences between once daily and twice daily gentamicin dosage in newborns with suspected sepsis. Pharm. World Sci. 31: 1823.

Javed, U.; Khan, MZ.; Saleemi, MK.; Khan, A.; Javed, I. and Rafique, S. (2013): Toxicopathological Effects of Parenteral Administration of Gentamicin in Growing Broilers. Int J Agric Biol. 15: 529-534.

Islam, NU.; Khan, MZ.; Saleemi, MK.; Khan, A.; Bhatti, SA.; Yousaf, M. and Hassan, ZU. (2011): Clinicopathological studies on gentamicin toxicity in White Leghorn commercial layers. Pak. Vet. J. 3: 305-308.

Itoh, N. and Okada, H. (1993): Pharmacokinetics and potential use of gentamicin in budgerigars (Melopsittacus undulatus). Zentralbl. Veterinarmed. A. 40: 194-199.

Kadkhodaee, M.; Khastar, H.; Arab, HA.; Ghaznavi, R.; Zahmatkesh, M. Mahdavi-Mazdeh, M. (2007): Antioxidant vitamins preserve superoxide dismutase activities in gentamicininduced nephrotoxicity. Transplant.Proc. 39: 864-865.

Kang, C.; Lee, H.; Hah, DY.; Heo, JH.; Kim, CH.; Kim, E. and Kim, JS. (2013): Protective Effects of Houttuynia cordata Thunb. on Gentamicin-induced Oxidative Stress and Nephrotoxicity in Rats. Toxicol Res. 29: 61-67.

Karadeniz, A.; Yildirim, A.; Simsek, N.; Kalkan, Y. and Celebi, F. (2008): Spirulina platensis protect against gentamicin-induced nephrotoxicity in rats. Phytother. Res. 22: 1506-1510.

Khan, I.; Khan, MZ.; Saleemi, MK.; Javed, I. and Khan, A. (2008): Pathological and biochemical effects of intramuscular gentamicin administration in chicken. Turk. J. Vet. Anim. Sci. 32: 345-351.

Khan, SA.; Priyamvada, S.; Farooq, N.; Khan, S.; Khan, MW. and Yusufi, AN. (2009): Protective effect of green tea extract on gentamicininduced nephrotoxicity and oxidative damage in rat kidney. Pharmacological Research. 59: 254-262.

Koyner, JL.; SherAli, R. and Murray, PT. (2008): Antioxidants. Do they have a place in the prevention or therapy of acute kidney injury? Nephron. Exp. Nephrol. 109: e109-e117.
Kumar, PS.; Mishra, D.; Ghosh, G. and Panda, GS. (2010): Medicinal uses and pharmacological properties of Moringa oleifera. Int. J. Phytomed. 2: 210-216.

Lee, IC.; Kim, SH.; Lee, SM.; Baek, HS.; Moon, C.; Kim, SH.; Park, SC.; Kim, HC. and Kim, JC. (2012): Melatonin attenuates gentamicininduced nephrotoxicity and oxidative stress in rats. Arch Toxicol. 86: 1527-1536.

Manguro, LO. and Lemmen, P. (2007): Phenolics of Moringa oleifera leaves. Nat. Prod. Res. 21: 56-68.

Martínez-Salgado, C.; Eleno, N.; Tavares, P.; Rodríguez-Barbero, A.; García-Criado, J.; Bolaños, JP. and López-Novoa, JM. (2002): Involvement of reactive oxygen species on gentamicin-induced mesangial cell activation. Kidney Int. 62: 1682-1692.

Morales, AI.; Detaille, D.; Prieto, M.; Puente, A.; Briones, E.; Arévalo, M.; Leverve, X.; LópezNovoa, JM. and El-Mir, MY. (2010): Metformin prevents experimental gentamicininduced nephropathy by a mitochondriadependent pathway. Kidney Int. 77: 861-869.

Nagai J. (2006): Molecular mechanisms underlying renal accumulation of aminoglycoside antibiotics and mechanism-based approach for developing nonnephrotoxic aminoglycoside therapy. Yakugaku Zasshi. 126: 327-335.

Nagai, J. and Takano, M. (2004): Molecular aspects of renal handling of aminoglycosides and strategies for preventing the nephrotoxicity. Drug Metab Pharmacokinet. 19: 159-170.

Nakajima, T.; Hishida, A. and Kato, A. (1994): Mechanisms for protective effects of free radical scavengers on gentamicin-mediated nephropathy in rats. American Journal of Physiology 266: F425-F431.

Paoletti, F. and Macali, A. (1990): Determination of superoxide disumutase activity by purely chemical system based on NAD (P) H oxidation. Methods Enzymol. 186: 209-220.

Polat, A.; Parlakpinar, H.; Tasdemir, S.; Colak, C.; Vardi, N.; Ucar, M.; Emre, MH. and Acet, A. (2006): Protective role of aminoguanidine on gentamicin-induced acute renal failure in rats. Acta Histochemica. 108: 365-371.

Ramachandran, C.; Peter, KV. and Gopalakrishnan, PK. (1980): Drumstick (Moringa oleifera): a multipurpose Indian vegetable. Econ.Bot. 34: 276-283.

Romero, F.; Perez, M.; Chavez, M.; Parra, G. and Durante, P. (2009): Effect of uric acid on gentamicin-induced nephrotoxicity in rats role of matrix metalloproteinases 2 and 9 . Basic Clin Pharmacol Toxicol. 105: 416-424.

Saleemi, MK.; Khan, MZ.; Khan, A. and Javed, I. (2009): Pathological effects of gentamicin administered intramuscularly to day old 
broiler chicks. Exp. Toxicol Pathol. 61: 425-432.

Sandhu, JS.; Sehgal, A.; Gupta, O. and Singh, A. (2007): Aminoglycoside nephrotoxicity revisited. J Ind Acad Clin Med. 8: 331-333.

Schmidt, RE.; Reavill, DR. and Phalen, DN. (2003): Urinary system. In: Pathology of pet and aviary birds. Ames (IA): Iowa State Press; p.95-107.

Sharma, $R$. and Singh, $V$ J. (2010): In vivo antioxidant activity of Moringa oleifera leaf and pod extracts against carbon tetra chloride induced liver damage in albino mice. J Chem Pharm Res. 2: 275-283.

Shirwaikar, A.; Malini, S. and Kumari, SC. (2003): Protective effect of Pongamia pinnata flowers against cisplatin and gentamicin induced nephrotoxicity in rats Indian J Exp Biol. 41: 58-62.

Sinha, AK. (1972): Colorimetric assay of catalase. Analytical biochemistry 47: 389-394.

Sreelatha, S. and Padma, PR. (2009): Antioxidant activity and total phenolic content of Moringa oleifera leaves in two stages of maturity. Plant Foods Hum Nutr. 64: 303-311.

Swan, SK. (1997): Aminoglycoside nephrotoxicity: review. Seminars in nephrology. 17: 27-33.

Tavafi, M. and Ahmadvand, H. (2011): Effect of rosmarinic acid on inhibition of gentamicin induced nephrotoxicity in rats. Tissue Cell. 43: 392-397.

Tennant, BC. and Center, SA. (2008): Hepatic function. In Kaneko J.J., Harvey J.W., Bruss
M.L. (Eds.), Clinical Biochemistry of Domestic Animals. Sixth Edition. Academic Press; New York; p.379-412.

Tulkens, PM. (1999): Nephrotoxicity of aminoglycoside antibiotics. Toxicol Lett. 46: 727-737.

Verma, AR.; Vijayakumar, M.; Mathela, CS. and Rao, CV. (2009): In vitro and in vivo antioxidant properties of different fractions of Moringa oleifera leaves. Food Chem Toxicol. 47: 2196-2201.

Walker, PD.; Barri, Y. and Shah, SV. (1999): Oxidant mechanisms in gentamicin nephrotoxicity. Ren Fail. 21: 433-442.

Watanabe, A.; Nagai, J.; Adachi, Y.; Katsube, T.; Kitahara, Y.; Murakami, T. and Takano, M. (2004): Targeted prevention of renal accumulation and toxicity of gentamicin by aminoglycoside building receptor antagonist. $\mathbf{J}$ Control Release 95: 423-433.

Yaman, I. and Balikci, E. (2010): Protective effect of Nigella sativa against gentamicin-induced nephrotoxcity in rats. Exp. Toxicol. Pathol. 62: 183-190.

Yang, C L.; Du, X H. and Han, YX. (1995): Renal cortical mitochondria are the source of oxygen free radicals enhanced by gentamicin. Renal Failure 17: 21-26.

Yoshiyama, Y.; Kobayashi, T.; Tomonaga, F. and Nakano, S. (1992): Chronotoxical study of gentamicin induced nephrotoxicity in rats. J. Antibiot. 45: 806-808.

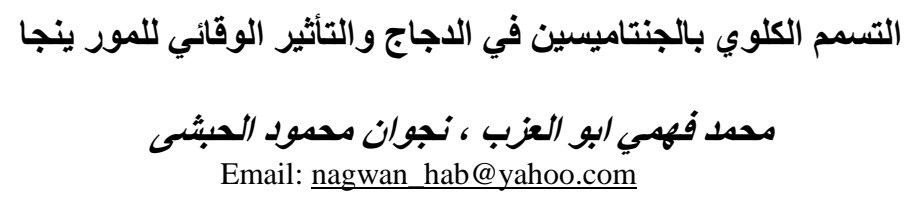

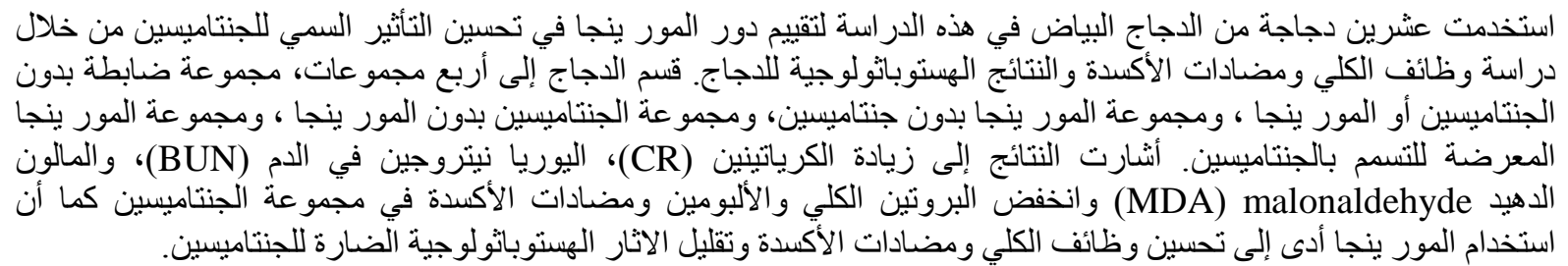

